\title{
BMJ Open The relative importance of perceived doctor's attitude on the decision to consult for symptomatic osteoarthritis: a choice-based conjoint analysis study
}

\author{
Domenica Coxon, ${ }^{1,2}$ Martin Frisher, ${ }^{3}$ Clare Jinks, ${ }^{1}$ Kelvin Jordan, ${ }^{1}$ Zoe Paskins, ${ }^{1}$ \\ George Peat ${ }^{1}$
}

To cite: Coxon D, Frisher M, Jinks $\mathrm{C}$, et al. The relative importance of perceived doctor's attitude on the decision to consult for symptomatic osteoarthritis: a choice-based conjoint analysis study. BMJ Open 2015;5:e009625.

doi:10.1136/bmjopen-2015009625

- Prepublication history and additional material is available. To view please visit the journal (http://dx.doi.org/ 10.1136/bmjopen-2015009625).

Received 4 August 2015 Revised 9 September 2015 Accepted 11 September 2015

\section{CrossMark}

${ }^{1}$ Arthritis Research UK Primary Care Centre, Research Institute for Primary Care \& Health Sciences, Keele University, Keele, UK

${ }^{2}$ Centre for Population Health Sciences, The University of Edinburgh, Edinburgh, UK ${ }^{3}$ The School of Pharmacy, Keele University, Keele, UK

Correspondence to Professor George Peat; g.m.peat@keele.ac.uk

\section{ABSTRACT}

Objectives: Some patients spend years with painful osteoarthritis without consulting for it, including times when they are experiencing persistent severe pain and disability. Beliefs about osteoarthritis and what primary care has to offer may influence the decision to consult but their relative importance has seldom been quantified. We sought to investigate the relative importance of perceived service-related and clinical need attributes in the decision to consult a primary care physician for painful osteoarthritis.

Design: Partial-profile choice-based conjoint analysis study, using a self-complete questionnaire containing 10 choice tasks, each presenting two scenarios based on a combination of three out of six selected attributes.

Setting: General population.

Participants: Adults aged 50 years and over with hip, knee or hand pain registered with four UK general practices.

Outcome measures: Relative importance of pain characteristics, level of disruption to everyday life, extent of comorbidity, assessment, management, perceived general practitioner (GP) attitude.

Results: 863 (74\%) people responded (55\% female; mean age 70 years, range: 58-93). The most important determinants of the patient's decision to consult the GP for joint pain were the extent to which pain disrupted everyday life ('most' vs 'none': relative importance 31\%) and perceived GP attitude ('legitimate problem, requires treatment' vs 'part of the normal ageing process that one just has to accept': $24 \%$ ). Thoroughness of assessment (14\%), management options offered $(13 \%)$, comorbidity $(13 \%)$ and pain characteristics $(5 \%)$ were less strongly associated with the decision to consult.

Conclusions: Anticipating that the GP will regard joint pain as 'part of the normal ageing process that one just has to accept' is a strong disincentive to seeking help, potentially outweighing other aspects of quality of care. Alongside the recognition and management of disrupted function, an important goal of each primary care consultation for osteoarthritis should be to avoid imparting or reinforcing this perception.

\section{Strengths and limitations of this study}

- Unlike many previous studies of what determines the decision (not) to consult for painful osteoarthritis, by using a conjoint analysis design we were able to quantify the relative importance of both service-related factors and patient/problem characteristics.

- Our study was large, recruited participants across a wide spectrum of characteristics and severity, had a high response rate and involved members of the public in the design stages through a series of meetings and qualitative developmental studies.

- The preference for pen-and-paper administration and the complex nature of the attributes meant that we could only include six potentially important determinants of the decision to consult and we were unable to estimate precisely the effect of interactions between determinants.

\section{INTRODUCTION}

Osteoarthritis has a substantial and growing impact on population health, ${ }^{1}{ }^{2}$ health services $^{3}$ and economies worldwide. ${ }^{4}$ Rising rates of primary hip and knee arthroplasty ${ }^{5}$ and projected future increases in prevalence driven by changes in population age structure and in rates of obesity and sedentary behaviour have prompted increasing calls for greater emphasis on prevention and control $^{6}$ and 'concerted public health and highquality integrated medical care'. 7 Yet it appears that some patients may spend years with painful osteoarthritis without consulting for their joint problem, ${ }^{8-11}$ including times when they are experiencing persistent severe pain and disability. ${ }^{12} 13$ This is despite the fact that most such individuals will continue to consult for other comorbid conditions and that there are a wide range of recommended non-surgical management options. ${ }^{14-16}$ Understanding what influences 
the decision to consult primary care is therefore important for identifying barriers to meeting the needs of patients with this common chronic condition.

There is a wealth of studies on the determinants of healthcare utilisation in general. ${ }^{17}{ }^{18}$ Studies specifically designed to reveal the determinants of primary care consultation for joint pain and osteoarthritis have been of broadly two types: quantitative observational studies comparing the particular characteristics of consulters and non-consulters and qualitative studies on osteoarthritis patients' experiences of primary healthcare and their reasons for seeking help. ${ }^{19}$ While the degree of disruption to daily activities emerges fairly consistently as a need-related determinant of consultation, qualitative studies have identified several potentially powerful beliefs about osteoarthritis and what primary care has to offer. They include beliefs and expectations on adequate clinical assessment,${ }^{20}$ the perception of a limited repertoire of effective treatments, ${ }^{21} 22$ the attribution of symptoms to 'normal ageing, ${ }^{13}{ }^{23}$ the importance of judging symptoms as "unusual'22 and competing priorities from comorbid illness. ${ }^{24}$ These may vary within individuals over time and many are likely to be shared by health professionals and patients alike. However, their relative importance has seldom been quantified. ${ }^{25} 26$

Therefore, the aim of our study was to quantitatively estimate the relative importance of some of these perceptions of osteoarthritis primary care against established need-related factors on patients' willingness to visit the doctor. To achieve this we undertook a conjoint analysis study in a community sample of adults aged 50 years and over with peripheral joint pain.

\section{METHODS}

\section{Overview of design}

The design was a partial-profile choice-based conjoint analysis study, administered as a single postal selfcomplete questionnaire that was mailed in February 2011 to 1170 adults aged over 50 years with hip, knee or hand pain and registered with one of four general practices in North Staffordshire, UK. Participants were members of an existing population observational cohort intended to describe and predict the long-term course of joint pain and osteoarthritis-the North Staffordshire Osteoarthritis Project (NorStOP1 \& NorStOP2). ${ }^{27} 28$ The NorStOP cohorts were formed in 2002-2003 with a census survey (two-stage postal questionnaire) of all adults aged 50 years and over registered with participating general practices. To be eligible for inclusion in the current study, NorStOP cohort members had to have consented to further contact at baseline, 3 and 6-year follow-up, have reported hip, knee or hand pain in the past 12 months at 6-year follow-up, still be alive and registered with the practice at the time of mailout, and not be currently participating in other research studies in the Institute. The list of potentially eligible cohort members was then screened by the lead general practitioner (GP) at each practice to exclude vulnerable groups, for example, new-onset dementia or severe/terminal illness. Conjoint analysis and discrete choice experiments cover a range of quantitative methods for eliciting preferences and have been used previously to elicit patients' preferences for access, content, style and provider of UK primary care consultations, ${ }^{29-35}$ out-of-hours care ${ }^{36}{ }^{37}$ and knee osteoarthritis patients' and practitioners' preferences for treatment. ${ }^{38-43}$ In conjoint analysis, respondents' preferences or values for various health states or services are elicited over a range of attributes and levels that define profiles in a series of choice tasks. ${ }^{44}$ Our study, including the selection of attributes and levels to characterise relevant profiles, was designed with specific reference to guidance on good research practices for conjoint analysis, ${ }^{44}$ other key methodology sources ${ }^{45-47}$ and with close patient/public involvement via our Institute's Research User Group (RUG). ${ }^{48}$ The RUG, originally formed in 2006, was established as dedicated infrastructure to support strong patient and public involvement (PPI) to ensure that our research leads to improvements in health policy, clinical practice and patient benefit. It now comprises over 75 members with a dedicated Coordinator and Support Assistant. Members of the RUG collaborate with researchers to maintain a focus on the patient perspective through their contributions to formulating research questions, advising on methods (questionnaire design, recruitment and consent procedures), interpreting findings and advising on dissemination strategies.

\section{Design of questionnaire and choice task}

We selected and specified salient attributes, levels and profiles based on the following main sources: (1) a narrative review of published studies of the determinants of primary care consultation for joint pain or osteoarthritis; ${ }^{9} 1213252649-58$ (2) a review of 15 previous conjoint analysis studies of, or including, aspects of the primary care consultation, ${ }^{29-37}$ 59-64 (3) cognitive interviews with three RUG members aged 50 years with experience of long-term joint pain and focused discussion groups with 10 RUG members. From these sources, and being mindful of RUG members' consistent preference for simple pen-and-paper format and their concern to minimise respondent burden, we selected three clinical need-related attributes and three service-related attributes (table 1). RUG members checked the phrasing of attribute levels for comprehension. The two 2-level attributes and four 3-level attributes created 324 possible scenarios.

We used pairwise choice sets: for each choice set respondents were presented with two alternative scenarios and invited to indicate under which they would be more likely to go to the GP. Owing to the relatively complex attributes and levels in this study, RUG members felt that scenarios with more than three attributes to consider in each choice task would be cognitively burdensome. We therefore chose a partial-profile 
Table 1 Attributes and levels included in choice tasks

\begin{tabular}{|c|c|c|}
\hline \multicolumn{2}{|c|}{ Attributes } & \multirow{2}{*}{$\begin{array}{l}\text { Levels } \\
\text { You are experiencing a dull aching pain, which is there most of the time } \\
\text { You are experiencing short episodes of more severe, often unpredictable pain }\end{array}$} \\
\hline 1 & Pain characteristics & \\
\hline \multirow[t]{3}{*}{2} & Level of disruption to & The pain is not disrupting your everyday life \\
\hline & everyday life & The pain is disrupting some of your everyday life \\
\hline & & The pain is disrupting most of your everyday life \\
\hline \multirow[t]{3}{*}{3} & Comorbidity & You are experiencing no other physical health problems \\
\hline & & You are experiencing other minor physical health problems \\
\hline & & You are experiencing other major physical health problems \\
\hline \multirow[t]{3}{*}{4} & Assessment & The GP asks about your symptoms and their effect on your day-to-day life \\
\hline & & $\begin{array}{l}\text { The GP conducts a thorough physical examination of the joints as well as asks about your } \\
\text { symptoms and their effect on your day-to-day life }\end{array}$ \\
\hline & & $\begin{array}{l}\text { The GP investigates with appropriate X-rays and blood tests as well as asks about your symptoms } \\
\text { and their effect on your day-to-day life and conducts a thorough physical examination of the joints }\end{array}$ \\
\hline \multirow[t]{3}{*}{5} & Management & The GP prescribes pain relief and gives verbal advice about your condition \\
\hline & & $\begin{array}{l}\text { The GP prescribes pain relief, gives written advice about your condition and arranges follow-up } \\
\text { with a practice nurse and physiotherapy referral }\end{array}$ \\
\hline & & $\begin{array}{l}\text { The GP offers a promising new treatment as well as prescribing pain relief, giving written advice } \\
\text { about your condition and arranging follow-up with a practice nurse and physiotherapy referral }\end{array}$ \\
\hline 6 & GP attitude & $\begin{array}{l}\text { The GP regards your joint pain as part of the normal ageing process that one just has to accept } \\
\text { The GP regards your joint pain as a legitimate health problem that requires treatment }\end{array}$ \\
\hline
\end{tabular}

design, randomly rotating attribute levels into the choice sets, such that across all choice sets each respondent would still typically consider all attributes and levels ${ }^{65}$ (sample choice task in figure 1).

We used the Advanced Design Module within Sawtooth Software SSI Web (V.7.0) to evaluate the relative statistical efficiency by simulating different numbers of choice sets and questionnaire versions. The combination of 10 choice sets per participant and 10 questionnaire versions based on a conservative estimate of 400 respondents $(<40 \%$ response) offered acceptably precise estimates of main effects (SEs $<0.05)$.

In addition to the 10 choice sets, the 26-page survey questionnaire included one closed question on the perceived difficulty of the choice tasks (response options: not at all hard, a little hard, quite hard, very hard, extremely hard) and sections on joint pain (previous history, recent healthcare use, Brief Illness Perceptions Questionnaire: Revised, ${ }^{66}$ and basic sociodemographic characteristics).

\section{Survey administration}

The survey was administered using a standard 3-stage mailing procedure with initial mailout of questionnaire and patient information sheet. Non-respondents were sent a reminder postcard at 2 weeks, followed by a repeat questionnaire at 4 weeks.

\section{Statistical analysis}

We analysed responses to the choice tasks by multinomial logistic regression using the aggregate logit function in CBC for SSI Web software (Sawtooth Software, Inc, Orem, Utah, USA). We estimated standardised utilities and SEs for each of the attribute levels. These utilities are zero-centred within each attribute and thus the values are relative, not absolute-for example, a negative utility value is interpreted as meaning only that this attribute level was associated with a lower likelihood of consulting relative to the other levels of that attribute. We then calculated the relative importance of each attribute as the range in utility estimates within an attribute divided by the sum of the ranges in utility estimates for all attributes, expressed as a percentage. ${ }^{67}$ This measure of the relative importance of each attribute is study-specific (ie, must be interpreted in the context of the attributes in the model and the levels of those attributes).

We looked at specific scenarios in which the overall utilities of two paired profiles were directly compared to predict which profile was more likely to lead to general practice consultation. The higher the overall utility of the profile, the greater is the relative propensity to consult. The utilities can be used to estimate strengths of preference for each profile, and results are accumulated over respondents to provide shares of preference among scenarios. The profile utilities are exponentiated and shares are normalised to sum to $100 \%$.

\section{RESULTS}

\section{Response and descriptive characteristics}

Of 1170 mailed, 10 were subsequently excluded having either recently died, left the practice or were no longer at the address. A further 297 potential participants refused or did not respond, leaving 863 respondents (mean age 70 years (SD 7.5); $55 \%$ female; response rate $74 \% .{ }^{68}$ The descriptive characteristics of respondents are provided in table 2. Respondents were younger than 
Figure 1 Sample page in the questionnaire showing the choice task format. GP, general practitioner.

Choice Task I

Imagine that your joint problem and your general health are changeable. Put yourself in each of the situations below, then choose the one that you think would more likely lead you to consult the general practitioner about your joint pain. Please read each situation carefully and, when you have made your choice, PUT A CROSS IN ONE BOX ONLY
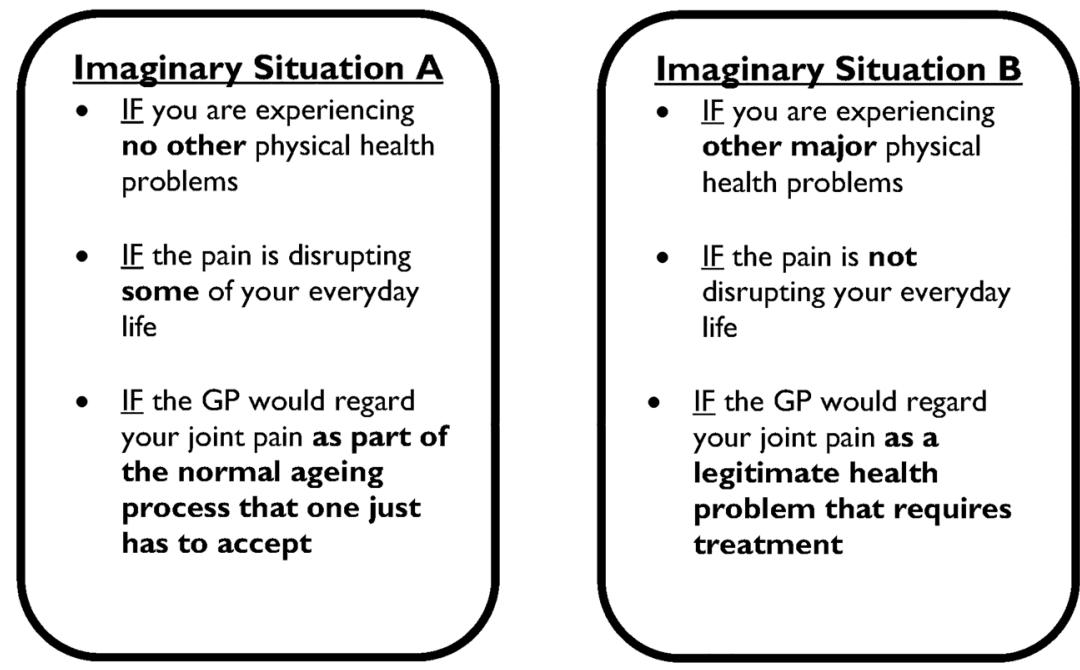

I would be more likely to consult the doctor about the joint problem if I was in...

\begin{tabular}{|c|}
\hline Situation A \\
\hline$\square$ \\
\hline
\end{tabular}

\begin{tabular}{|c|}
\hline Situation B \\
\hline$\square$ \\
\hline
\end{tabular}

non-respondents/refusals but did not differ on other measured sociodemographic factors (see online supplementary material file).

\section{Relative importance of attributes}

The choice tasks were well-completed ( $<5 \%$ missing) with most respondents rating them as 'not at all hard' or 'a little hard'. Table 3 illustrates the standardised, zerocentred partworth utilities for all attribute levels and the attribute utility ranges, which form the basis for quantifying the relative importance of the attributes. The level of disruption to everyday life had the highest relative importance on the decision to consult $(31 \%)$, followed by GP attitude $(24 \%)$.

\section{Pairwise scenarios}

Proposition 1: Changing to a (GP with a) positive legitimising attitude would precipitate the presentation

of less disabling joint problems

The pairwise analysis in table 4 suggests that, assuming all other factors are equal, $65 \%$ of respondents would rather consult with a joint problem that was causing some disruption to their everyday life if the GP was expected to have a 'legitimising' attitude (scenario A) than consult if their joint problem that was causing greater disruption to their everyday life but they expected the GP to have a 'normal ageing-accept it' attitude (scenario B).

\section{Proposition 2: Changing to a (GP with a) positive} legitimising GP attitude would encourage consultation more than the availability of thorough examination, investigations, new treatments and best-evidence management options

Almost half $(48 \%)$ of respondents would opt to consult a GP with a 'legitimising' attitude offering basic assessment and management options (scenario A) than a GP offering a full range of investigations and treatments but who was perceived to have a 'normal ageing-accept it' attitude (scenario B; table 4).

\section{DISCUSSION}

Our conjoint analysis study confirms the importance of disability severity in determining the decision to consult 
Table 2 Descriptive characteristics of respondents

Respondents $(n=863)$

\section{Age (years) \\ 50-64 \\ $65-74$ \\ $75+$}

$245(28)$

$367(43)$

$251(29)$

$478(55)$

Female

$185(21)$

Lives alone

Currently in full-time or part-time paid

employment

Occupational class*

Higher managerial, administrative and

professional occupations

Intermediate occupations

Routine and manual occupations

Perceived financial strain: "quite

comfortably off' $\dagger$

Self-rated health: fair/poor

Number of self-reported comorbidities

(0-22): median (IQR)

HADS (0-21): median (IQR)

Anxiety

Depression

Hip pain in past 12 months

Knee pain in past 12 months

$196(24)$

$203(25)$

$190(23)$

$418(52)$

$150(17)$

$224(26)$

$4(2,6)$

Hand pain in past 12 months

Time since onset of joint problem (years)

$<1$

$1-5$

$6-10$

$>10$

Never consulted GP for joint problem

Consulted GP for joint problem in past

12 months

Figures are numbers (percentage) of respondents unless

otherwise stated.

*Standard occupational classification based on current/last job title. ${ }^{71} 72$

†From Thomas. $^{70}$

GP, general practitioner; HADS, Hospital Anxiety and Depression Scale. ${ }^{69}$

for peripheral joint osteoarthritis but provides new quantitative evidence on the relative importance of perceived GP attitude. Anticipating an 'it's normal ageing-accept it' attitude was a strong disincentive to consulting having a stronger influence than intermittent, severe episodes of pain, competing comorbidities and the level of assessment and range of treatment options being offered. The majority of respondents indicated they would opt to consult a GP with a 'legitimising' attitude when experiencing less severe disability before they would visit a GP with 'normal ageing-accept it' when their disability was worse.

The clear association between degree of disrupted function and consultation for osteoarthritis is uncontentious and consistent with many previous studies. ${ }^{19}$ However, the relative importance of perceived doctor's attitude is novel and requires more careful interpretation. Access to healthcare can be considered through Wood et $a l^{73}$,s notion of 'candidacy', which refers to negotiation around an individual's eligibility for healthcare involving interaction between the health professional and patient, and which is influenced by cultural values. ${ }^{74}$ Legitimisation by the GP appears valued by patients and may be important to their perception as a good 'candidate' for consulting. Conversely a lack of legitimisation, whether experienced, perceived or anticipated, is likely to discourage consultation and the reporting of symptoms, a finding previously reported by McHugh et $a l^{75}$ and $\operatorname{Haas}^{60}$ and consistent with the importance of the endorsement and support of trusted primary healthcare professionals to accessing and adhering to arthritis self-management programmes. ${ }^{76}$ However, it is important not to over-interpret our findings. It must be borne in mind that our study does not provide evidence of the frequency with which persons with osteoarthritis feel their problem is not legitimised by their GP, merely that when this is the case it acts as a strong disincentive to consulting. A significant minority of participants in this study $(17 \%)$ attributed their joint pain to 'ageing'. Given that patients may see several different GPs, it would be useful to understand the extent to which negative expectations are transferred by patients from one practitioner to another.

Compared with previously published conjoint analysis studies in health, ${ }^{77}$ the present study was large and had a high response rate (although the sample frame comprised existing cohort participants). We involved members of the RUG through a series of meetings and qualitative developmental studies and believe this contributed to the response rate and low respondent burden. However, we did not use formal consensus development methods ${ }^{78}$ to derive the final list of attributes nor, given the strong advice from the RUG to use traditional pen and paper format, did we use computerbased adaptive conjoint analysis which would have enabled the initial inclusion of more attributes. It therefore remains possible that other, more powerful determinants of the decision to consult were not included in our study and therefore our findings must be interpreted in the context of those chosen attributes and specified levels. In addition, it is important to note that the estimated partworth utilities will reflect the particular attribute levels chosen and how these are framed. The partial-profile design, while minimising respondent burden, does not fully permit the estimation of interactions ${ }^{65}$ and thus our study is limited to estimating main effects only. In the evaluation of the pairwise scenarios, an assumption is made that the two variables, for example, legitimising attitude of GP and availability of investigations, are mutually exclusive. Although this is unlikely to fully reflect the inter-relationships in the real world, it does serve to demonstrate the relative value participants place on each variable. Finally, as with all such cross-sectional studies, our findings are a snapshot particular to time, place and person, and future research 
Table 3 Perceived importance of attributes and levels from choice tasks

\begin{tabular}{|c|c|c|c|c|}
\hline Attributes and levels & $\begin{array}{l}\text { Number of times } \\
\text { selected/number of } \\
\text { times presented (\%) }\end{array}$ & $\begin{array}{l}\text { Standardised utility }(\beta) \\
(95 \% \mathrm{Cl})\end{array}$ & $\begin{array}{l}\text { Attribute } \\
\text { utility range }\end{array}$ & $\begin{array}{l}\text { Attribute } \\
\text { importance } \\
\text { scores }(\%)^{\star}\end{array}$ \\
\hline \multicolumn{5}{|l|}{ 1. Pain characteristics } \\
\hline Dull ache & $2040 / 4315(47)$ & $-0.08(-0.114$ to -0.048$)$ & 0.16 & 5 \\
\hline Severe unpredictable episodes & $2275 / 4315(53)$ & $0.08(0.048$ to 0.114$)$ & & \\
\hline \multicolumn{5}{|l|}{ 2. Level of disruption to everyday life } \\
\hline None & $835 / 2840(29)$ & $-0.65(-0.706$ to -0.590$)$ & 1.10 & 31 \\
\hline Some & $1590 / 2859(56)$ & $0.20(0.147$ to 0.255$)$ & & \\
\hline Most & $1892 / 2931(65)$ & 0.45 (0.392 to 0.502$)$ & & \\
\hline \multicolumn{5}{|l|}{ 3. Comorbidity } \\
\hline None & $1275 / 2944(43)$ & $-0.22(-0.276$ to -0.169$)$ & 0.46 & 13 \\
\hline Minor & $1390 / 2836(49)$ & $-0.01(-0.065$ to 0.044$)$ & & \\
\hline Major & $1651 / 2850(58)$ & $0.23(0.179$ to 0.287$)$ & & \\
\hline \multicolumn{5}{|l|}{ 4. Assessment } \\
\hline Asks about symptoms and impact & $1136 / 2853(40)$ & $-0.27(-0.328$ to -0.219$)$ & 0.48 & 14 \\
\hline As above plus thorough physical examination & $1507 / 2842(53)$ & $0.06(0.007$ to 0.117$)$ & & \\
\hline As above, appropriate X-rays /bloods & $1678 / 2935(57)$ & $0.21(0.157$ to 0.265$)$ & & \\
\hline \multicolumn{5}{|l|}{ 5. Management } \\
\hline Pain relief, verbal advice & $1178 / 2930(40)$ & $-0.26(-0.312$ to -0.208$)$ & 0.45 & 13 \\
\hline Pain relief, written advice, $\mathrm{PN}$ f/up, $\mathrm{PT}$ referral & $1530 / 2858(54)$ & $0.07(0.012$ to 0.120$)$ & & \\
\hline Pain relief, written advice, $\mathrm{PN}$ follow-up, $\mathrm{PT}$ referral, promising new treatment & $1609 / 2842(57)$ & $0.19(0.141$ to 0.247$)$ & & \\
\hline \multicolumn{5}{|l|}{ 6. GP attitude } \\
\hline Normal ageing, accept it & $1360 / 4315(32)$ & $-0.43(-0.466$ to -0.397$)$ & 0.86 & 24 \\
\hline Legitimate problem, requires treatment & $2955 / 4315(68)$ & $0.43(0.397$ to 0.466$)$ & & \\
\hline
\end{tabular}


Table 4 Paired analysis to evaluate specific hypotheses

\begin{tabular}{ll}
\hline Profile Attributes and levels & $\begin{array}{l}\text { Total Probability of } \\
\text { utility choosing profile* }(\%)\end{array}$ \\
\hline
\end{tabular}

Scenario 1: To what extent would changing to a (GP with a) positive legitimising attitude precipitate the presentation of less disabling joint problems?

A The pain is disrupting most of your everyday life AND The GP regards your joint $\quad \begin{array}{lll}0.02 & 35\end{array}$ pain as part of the normal ageing process that one just has to accept

B The pain is disrupting some of your everyday life AND The GP regards your joint $\quad \begin{array}{lll}0.63 & 65\end{array}$ pain as a legitimate health problem that requires treatment

Scenario 2: Trade-off between available primary care assessment and management options vs perceived GP attitude

A The GP investigates with appropriate X-rays and blood tests as well as asks about $\quad-0.03 \quad 52$ your symptoms and their effect on your day-to-day life and conducts a thorough physical examination of the joints AND The GP offers a promising new treatment as well as prescribing pain relief, giving written advice about your condition and arranging follow-up with a practice nurse and physiotherapy referral AND The GP regards your joint pain as part of the normal ageing process that one just has to accept

B The GP asks about your symptoms and their effect on your day-to-day life AND The GP prescribes pain relief and gives verbal advice about your condition AND $-0.10 \quad 48$ The GP regards your joint pain as a legitimate health problem that requires treatment

*Within each pairwise scenario, the probability of choosing a profile (A or B) as the one under which they would be more likely to consult the GP (all else being equal). Calculated as the exponentiated total utility/sum total of exponentiated utilities.

$\mathrm{GP}$, general practitioner.

might usefully attempt to replicate these findings in a different setting.

Anticipating that the GP will regard joint pain as 'part of the normal ageing process that one just has to accept' is a strong disincentive to seeking help, potentially outweighing other aspects of quality of care (such as offering practice nurse follow-up and physiotherapy referral). Alongside the recognition and management of disrupted function, an important goal of each primary care consultation for osteoarthritis should be to avoid imparting or reinforcing this perception. Currently ongoing research studies within our Institution that could inform how this might be achieved include detailed, systematic observation of 'negative talk' within the osteoarthritis consultation, ${ }^{76}$ and an evaluation of the effects of implementing a 'model OA consultation' with patient guidebook in primary care. ${ }^{79,}$

Acknowledgements The authors would like to thank participating patients and practices, and Charlotte Purcell, née Clements, Tracy Whitehurst and lan Thomas for their contributions to survey administration, and staff at SKIM Group Rotterdam for technical advice during the design and analysis of this study.

Contributors DC designed the study, co-ordinated and monitored data collection, contributed to drafting the analysis plan, analysis of data and interpretation of findings. GP and MF conceived the study and secured funding. DC, GP, MF, CJ contributed to the design of the study, interpretation of findings and drafting and revision of the manuscript. KJ contributed to the statistical analysis and interpretation of findings. All authors contributed to the drafting and revision of the manuscript and approved the final version.

Funding This study was supported by a Programme Grant from Arthritis Research UK (Chief Investigator: Professor George Peat; Grant Reference Number: 18175).

Competing interests None declared.
Ethics approval Staffordshire Research Ethics Committee (10/H1203/63).

Provenance and peer review Not commissioned; externally peer reviewed.

Data sharing statement The Centre has established data sharing arrangements to support joint publications and other research collaborations. Applications for access to anonymised data from our research databases are reviewed by the Centre's Data Custodian and Academic Proposal (DCAP) Committee and a decision regarding access to the data is made subject to the NRES ethical approval first provided for the study and to new analysis being proposed. Further information on our data sharing procedures can be found on the Centre's website (http://www.keele.ac.uk/pchs/publications/ datasharingresources/) or by emailing the Centre's data manager (primarycare.datasharing@keele.ac.uk).

Open Access This is an Open Access article distributed in accordance with the terms of the Creative Commons Attribution (CC BY 4.0) license, which permits others to distribute, remix, adapt and build upon this work, for commercial use, provided the original work is properly cited. See: http:// creativecommons.org/licenses/by/4.0/

\section{REFERENCES}

1. Vos T, Flaxman AD, Naghavi M, et al. Years lived with disability (YLDs) for 1160 sequelae of 289 diseases and injuries 1990-2010: a systematic analysis for the global burden of disease study 2010 . Lancet 2012;380:2163-96.

2. Cross M, Smith E, Hoy D, et al. The global burden of hip and knee osteoarthritis: estimates from the global burden of disease 2010 study. Ann Rheum Dis 2014;73:1323-30.

3. Turkiewicz A, Petersson IF, Björk J, et al. Current and future impact of osteoarthritis on health care: a population-based study with projections to year 2032. Osteoarthritis Cartilage 2014;22 1826-32.

4. Hiligsmann $\mathrm{M}$, Cooper $\mathrm{C}$, Arden $\mathrm{N}$, et al. Health economics in the field of osteoarthritis: an expert's consensus paper from the European Society for Clinical and Economic aspects of Osteoporosis and Osteoarthritis (ESCEO). Semin Arthritis Rheum 2013;43:303-13.

5. Culliford D, Maskell J, Judge A, et al. Future projections of total hip and knee arthroplasty in the UK: results from the UK clinical practice research datalink. Osteoarthritis Cartilage 2015;23:594-600.

6. Hoy DG, Smith E, Cross M, et al. Reflecting on the global burden of musculoskeletal conditions: lessons learnt from the global burden of 
disease 2010 study and the next steps forward. Ann Rheum Dis 2015;74:4-7.

7. Murray CJ, Richards MA, Newton JN, et al. UK health performance: findings of the global burden of disease study 2010. Lancet 2013;381:997-1020.

8. Jinks C, Jordan K, Ong BN, et al. A brief screening tool for knee pain in primary care (KNEST). 2. Results from a survey in the general population aged 50 and over. Rheumatology (Oxford) 2004;43:55-61.

9. Thorstensson CA, Gooberman-Hill R, Adamson J, et al. Help-seeking behaviour among people living with chronic hip or knee pain in the community. BMC Musculoskelet Disord 2009;10:153.

10. Sheikh L, Nicholl BI, Green DJ, et al. Osteoarthritis and the rule of halves. Osteoarthritis Cartilage 2014;22:535-9.

11. Turkiewicz A, Gerhardsson de Verdier M, Engström G, et al. Prevalence of knee pain and knee OA in southern Sweden and the proportion that seeks medical care. Rheumatology (Oxford) 2015;54:827-35.

12. Bedson J, Mottram S, Thomas E, et al. Knee pain and osteoarthritis in the general population: what influences patients to consult? Fam Pract 2007;24:443-53.

13. Jinks C, Ong BN, Richardson J. A mixed methods study to investigate needs assessment for knee pain and disability: population and individual perspectives. BMC Musculoskelet Disord 2007;8:59.

14. Zhang W, Nuki G, Moskowitz RW, et al. OARSI recommendations for the management of hip and knee osteoarthritis: part III: changes in evidence following systematic cumulative update of research published through January 2009. Osteoarthritis Cartilage 2010:18:476-99.

15. National Institute for Health and Care Excellence. Osteoarthritis. Care and management in adults. Clinical guideline CG177. National Clinical Guideline Centre, 2014.

16. McAlindon TE, Bannuru RR, Sullivan MC, et al. OARSI guidelines for the non-surgical management of knee osteoarthritis. Osteoarthritis Cartilage 2014;22:363-88.

17. de Boer AG, Wijker W, de Haes HC. Predictors of health care utilization in the chronically ill: a review of the literature. Health Policy 1997:42:101-15.

18. Babitsch B, Gohl D, von Lengerke T. Re-revisiting Andersen's behavioral model of health services use: a systematic review of studies from 1998-2011. Psychosoc Med 2012;9:Doc11.

19. Paskins Z, Sanders T, Hassell AB. What influences patients with osteoarthritis to consult their GP about their symptoms? A narrative review. BMC Fam Pract 2013;14:195.

20. Thomas MJ, Moore A, Roddy E, et al. 'Somebody to say come on we can sort this': a qualitative study of primary care consultation among older adults with symptomatic foot osteoarthritis. Arthritis Care Res (Hoboken) 2013;65:2051-5.

21. Sanders C, Donovan JL, Dieppe PA. Unmet need for joint replacement: a qualitative investigation of barriers to treatment among individuals with severe pain and disability of the hip and knee. Rheumatology (Oxford) 2004;43:353-7.

22. Morden A, Jinks C, Ong BN. Understanding help seeking for chronic joint pain: implications for providing supported self-management. Qual Health Res 2014;24:957-68.

23. Gignac MA, Davis AM, Hawker G, et al. 'What do you expect? you're just getting older': a comparison of perceived osteoarthritis-related and aging-related health experiences in middle- and older-age adults. Arthritis Rheum 2006:55:905-12.

24. Cheraghi-Sohi S, Bower P, Kennedy A, et al. Patient priorities in osteoarthritis and comorbid conditions: a secondary analysis of qualitative data. Arthritis Care Res (Hoboken) 2013;65:920-7.

25. Mitchell HL, Carr AJ, Scott DL. The management of knee pain in primary care: factors associated with consulting the GP and referrals to secondary care. Rheumatology (Oxford) 2006;45:771-6.

26. Hill S, Dziedzic K, Thomas E, et al. The illness perceptions associated with health and behavioural outcomes in people with musculoskeletal hand problems: findings from the north Staffordshire osteoarthritis project (NorStOP). Rheumatology (Oxford) 2007:46:944-51.

27. Thomas E, Wilkie R, Peat G, et al. The north Staffordshire osteoarthritis project-NorStOP: Prospective, 3-year study of the epidemiology and management of clinical osteoarthritis in a general population of older adults. BMC Musculoskelet Disord 2004;5:2.

28. Peat G, Thomas E, Handy J, et al. The Knee Clinical Assessment Study-CAS(K). A prospective study of knee pain and knee osteoarthritis in the general population. BMC Musculoskelet Disord 2004;5:4.
29. Vick S, Scott A. Agency in health care. Examining patients' preferences for attributes of the doctor-patient relationship. J Health Econ 1998;17:587-605.

30. Longo MF, Cohen DR, Hood K, et al. Involving patients in primary care consultations: assessing preferences using discrete choice experiments. Br J Gen Pract 2006;56:35-42.

31. Rubin G, Bate A, George A, et al. Preferences for access to the GP a discrete choice experiment. Br J Gen Pract 2006;56:743-8.

32. Turner $\mathrm{D}$, Tarrant $\mathrm{C}$, Windridge $\mathrm{K}$, et al. Do patients value continuity of care in general practice? An investigation using stated preference discrete choice experiments. J Health Serv Res Policy 2007;12:132-7.

33. Caldow J, Bond C, Ryan M, et al. Treatment of minor illness in primary care: a national survey of patient satisfaction, attitudes and preferences regarding a wider nursing role. Health Expect 2007;10:30-45.

34. Cheraghi-Sohi S, Hole AR, Mead N, et al. What patients want from primary care consultations: a discrete choice experiment to identify patients' priorities. Ann Fam Med 2008;6:107-15.

35. Gerard K, Salisbury C, Street D, et al. Is fast access to general practice all that should matter? A discrete choice experiment of patients' preferences. J Health Serv Res Policy 2008;13(Suppl 2):3-10.

36. Morgan A, Shackley P, Pickin M, et al. Quantifying patient preferences for out-of-hours primary care. J Health Serv Res Policy 2000:5:214-18.

37. Scott A, Watson MS, Ross S. Eliciting preferences of the community for out of hours care provided by general practitioners: a stated preference discrete choice experiment. Soc Sci Med 2003;56:803-14.

38. Fraenkel L, Bogardus ST Jr, Concato J, et al. Treatment options in knee osteoarthritis: the patient's perspective. Arch Intern Med 2004;164:1299-304.

39. Fraenkel L, Wittink DR, Concato J, et al. Informed choice and the widespread use of antiinflammatory drugs. Arthritis Rheum 2004;51:210-14.

40. Fraenkel L, Fried $\mathrm{T}$. If you want patients with knee osteoarthritis $(\mathrm{OA})$ to exercise: tell them about NSAIDS. Patient 2008;1:21-6.

41. Arden NK, Hauber AB, Mohamed AF, et al. How do physicians weigh benefits and risks associated with treatments in patients with osteoarthritis in the United Kingdom? J Rheumatol 2012;39:1056-63.

42. Hauber AB, Arden NK, Mohamed AF, et al. A discrete-choice experiment of United Kingdom patients' willingness to risk adverse events for improved function and pain control in osteoarthritis. Osteoarthritis Cartilage 2013;21:289-97.

43. Laba TL, Brien JA, Fransen M, et al. Patient preferences for adherence to treatment for osteoarthritis: the MEdication Decisions in Osteoarthritis Study (MEDOS). BMC Musculoskelet Disord 2013;14:160.

44. Bridges JF, Hauber AB, Marshall D, et al. Conjoint analysis applications in health-a checklist: a report of the ISPOR good research practices for conjoint analysis task force. Value Health 2011;14:403-13.

45. Lancsar E, Louviere J. Conducting discrete choice experiments to inform healthcare decision making: a user's guide. Pharmacoeconomics 2008;26:661-77.

46. Ryan M, Gerard K, Amaya-Amaya M, eds. Using discrete choice experiments to value health and health care. 1st edn. Dordrecht: Springer, 2008.

47. Orme B. Getting started with conjoint analysis: strategies for product design and pricing research. 2nd edn. Madison, Wisconsin: Research Publishers LLC, 2010:57-66.

48. Jinks $C$, Carter $P$, Rhodes $C$, et al. Sustaining patient and public involvement in research. J Care Services Manag 2013;7:146-54.

49. Jordan $\mathrm{K}$, Jinks $\mathrm{C}$, Croft $\mathrm{P}$. A prospective study of the consulting behaviour of older people with knee pain. Br J Gen Pract 2006;56:269-76.

50. Rosemann T, Joos S, Szecsenyi J, et al. Health service utilization patterns of primary care patients with osteoarthritis. BMC Health Serv Res 2007;7:169.

51. Rosemann T, Gensichen J, Sauer N, et al. The impact of concomitant depression on quality of life and health service utilisation in patients with osteoarthritis. Rheumatol Int 2007;27:859-63.

52. Cronan TA, Shaw WS, Gallagher RA, et al. Predicting health care use among older osteoarthritis patients in an HMO. Arthritis Care Res 1995;8:66-72.

53. Hopman-Rock M, de Bock GH, Bijlsma JW, et al. The pattern of health care utilization of elderly people with arthritic pain in the hip or knee. Int J Qual Health Care 1997;9:129-37. 
54. Rao JK, Callahan LF, Helmick CG III. Characteristics of persons with self-reported arthritis and other rheumatic conditions who do not see a doctor. J Rheumatol 1997;24:169-73.

55. Dieppe P, Basler HD, Chard J, et al. Knee replacement surgery for osteoarthritis: effectiveness, practice variations, indications and possible determinants of utilization. Rheumatology (Oxford) 1999;38:73-83.

56. Ethgen $\mathrm{O}$, Kahler $\mathrm{KH}$, Kong $\mathrm{SX}$, et al. The effect of health related quality of life on reported use of health care resources in patients with osteoarthritis and rheumatoid arthritis: a longitudinal analysis. $J$ Rheumatol 2002;29:1147-55.

57. Dominick KL, Ahern FM, Gold CH, et al. Health-related quality of life and health service use among older adults with osteoarthritis. Arthritis Rheum 2004;51:326-31.

58. Kim MY, Park JK, Koh SB, et al. Factors influencing utilization of medical care among osteoarthritis patients in Korea: using 2005 Korean National Health and Nutrition Survey data. J Prev Med Public Health 2010;43:513-22.

59. Fiebig DG, Haas M, Hossain I, et al. Decisions about pap tests: what influences women and providers? Soc Sci Med 2009;68:1766-74.

60. Haas M. The impact of non-health attributes of care on patients' choice of GP. Aust J Prim Health 2005;11:40-6.

61. Hjelmgren J, Anell A. Population preferences and choice of primary care models: a discrete choice experiment in Sweden. Health Policy 2007;83:314-22.

62. Markham FW, Diamond JJ, Hermansen CL. The use of conjoint analysis to study patient satisfaction. Eval Health Prof 1999;22:371-8.

63. Ryan M, Mclntosh E, Shackley P. Using conjoint analysis to elicit the views of health service users: an application to the patient health card. Health Expect 1998;1:117-29.

64. Scott A, Vick S. Patients, doctors and contracts: an application of principal-agent theory to the doctor-patient relationship. Scott $J$ Political Economy 1999;46:111-34.

65. Patterson M, Chrzan K. Partial profile discrete choice: what's the optimal number of attributes? Sawtooth Software Conference Proceedings; 6-8 October 2004:173-85.

66. Broadbent E, Petrie KJ, Main J, et al. The brief illness perception questionnaire. J Psychosom Res 2006;60:631-7.

67. Orme B. Getting started with conjoint analysis: strategies for product design and pricing research. 1st edn. Glendale, CA: Research Publishers LLC, 2005.
68. The American Association for Public Opinion Research. Standard definitions: final disposition of case codes and outcome rates in surveys. 7th edn. 2011.

69. Zigmond AS, Snaith RP. The hospital anxiety and depression scale. Acta Psychiatr Scand 1983;67:361-70.

70. Thomas R. Income. A question bank topic commentary. Surrey. UK: University of Surrey, 1999. http://www.surveynet.ac.uk/sqb/topics/ commentaries.asp

71. Office for National Statistics, ed. Standard occupational classification 2000 (SOC 2000). London: Stationery Office, 2000.

72. Office for National Statistics, ed. National statistics socioeconomic classification (NS-SEC 2002). London: Stationery Office, 2002.

73. Woods MD, Kirk MD, Agarwal MS, et al. Vulnerable groups and access to health care: a critical interpretive review. Report for the National Co-ordinating Centre for NHS Service Delivery and Organisation R \& D (NCCSDO). 2005;27.

74. Paskins Z, Sanders T, Hassell AB. Comparison of patient experiences of the osteoarthritis consultation with GP attitudes and beliefs to OA: a narrative review. BMC Fam Pract 2014; 15:46.

75. McHugh GA, Silman AJ, Luker KA. Quality of care for people with osteoarthritis: a qualitative study. J Clin Nurs 2007;16:168-76.

76. Ackerman IN, Buchbinder R, Osborne RH. Factors limiting participation in arthritis self-management programmes: an exploration of barriers and patient preferences within a randomized controlled trial. Rheumatology (Oxford) 2013;52: 472-9.

77. Marshall D, Bridges JF, Hauber B, et al. Conjoint analysis applications in health-how are studies being designed and reported?: an update on current practice in the published literature between 2005 and 2008. Patient 2010;3:249-56.

78. Hiligsmann M, van Durme C, Geusens $\mathrm{P}$, et al. Nominal group technique to select attributes for discrete choice experiments: an example for drug treatment choice in osteoporosis. Patient Prefer Adherence 2013;7:133-9.

79. Dziedzic KS, Healey EL, Porcheret M, et al. Implementing the NICE osteoarthritis guidelines: a mixed methods study and cluster randomised trial of a model osteoarthritis consultation in primary care-the Management of OsteoArthritis In Consultations (MOSAICS) study protocol. Implement Sci 2014;9:95. 